\title{
CHARACTERIZATION AND EVALUATION OF HEAVY METAL POLLUTION IN SOIL-WHEAT SYSTEM AROUND COAL MINES IN PINGDINGSHAN, CHINA
}

\author{
ZhANG, W. P. ${ }^{1}-$ QIAN, J. ${ }^{1}-$ XU, G. J. ${ }^{1}-$ ZhANG, D. M. ${ }^{1}-$ KANG, C. ${ }^{1}-$ FenG, D. X. ${ }^{1}-$ ShI, L. $^{1}-$ \\ ZHANG, C. L. ${ }^{1,2^{*}}-$ GUO, Z. Y. ${ }^{* *}-$ MA, J. H. ${ }^{1,2}-$ ZHANG, C. S. ${ }^{1}$ \\ ${ }^{1}$ College of Environment and Planning, Henan University, Kaifeng 475001, China \\ ${ }^{2}$ Institute of Natural Resources and Environment, Henan University, Kaifeng 475001, China \\ ${ }^{3}$ School of Geography and Archaeology, National University of Ireland, Galway, Ireland \\ *Corresponding author \\ e-mail: zhangcl@henu.edu.cn, guozy9888@163.com; phone: +86-371-2388-1850; fax: +86-
} 378-2388-1850

(Received 6 ${ }^{\text {th }}$ Dec 2018; accepted $4^{\text {th }}$ Feb 2019)

\begin{abstract}
Indoor experiments were conducted to fully understand soil metal contamination around coal mines in Pingdingshan, Henan province, China. Forty-three paired soil and wheat product samples were collected from three main mining areas in Pingdingshan. Soil $\mathrm{Cd}, \mathrm{Zn}$ and $\mathrm{Pb}$ were assessed using the diffusive gradients in thin films (DGT) and pentetic acid or diethylene triamine penlaacetic acid (DTPA). The pollution levels were evaluated. The Nemero comprehensive pollution index shows the soil heavy metal pollution is slight; the single coefficient of potential ecological hazard indicates the soil pollution degree of heavy metals ranks as $\mathrm{Cd}>\mathrm{Pb}>\mathrm{Zn}$, which is the most serious pollution. $\mathrm{Cd}$ is close to medium ecological hazard, and other heavy metals are minor ecological hazards.
\end{abstract}

Keywords: coal mines, wheat, DGT, DTPA, potential ecological risk

\section{Introduction}

Mineral resources are the basic source of human production and life, and an important material basis for socioeconomic development. As the demand for energy has increased since the industrial revolution, the human society has increasingly exploited fossil energy such as coal. The development of mineral resources plays an important role in promoting the national economy growth, but has also brought some environmental pollution problems. During the mining process, heavy metals in coal and coal gangue can enter and the soil around mining areas through leaching, infiltration, migration and other ways. Heavy metal pollution in the soil affects the soil microbial activity and thus the structure and function of the soil ecosystem. Heavy metals in the soil enter the food chain through food and vegetables, causing health risks to humans.

Various heavy metal environmental pollutants have received much attention in recent years because of their persistent bioaccumulation and high toxicity.

Some heavy metals such as $\mathrm{Zn}$ and $\mathrm{Cu}$ above the safe concentration can be toxic, while other heavy metals can be harmful even at low concentrations. As reported, the farmland soil around a coal mine in north Bangladesh was severely contaminated by heavy metals such as $\mathrm{Mn}, \mathrm{Zn}, \mathrm{As}, \mathrm{Pb}$ and Ti (Bhuiyan et al., 2010). Behaddya et al. used GIS to characterize the spatial distribution of heavy metal pollution in the surface soil of a coal mine area in Algeria (Behaddya and Hadjel, 2014). However, the effective assessment of health risks to residents is of very insufficient. In this research, The 
objective of this study is used diffusive gradients in thin-films (DGT) to assess the heavy metal contents around the mining areas in Pingdingshan and to evaluate the heavy metal pollution levels and environmental risks.

\section{Materials and methods}

\section{Sampling and sample pretreatment}

Pingdingshan $\left(33^{\circ} 08^{\prime}-34^{\circ} 20^{\prime} \mathrm{N}, 112^{\circ} 14^{\prime}-113^{\circ} 45^{\prime} \mathrm{E}\right)$ in Henan Province is known as the coal bunker of middle China. It is also an important base of the energy and raw material industry. In this study, 42 paired samples of soil and wheat were collected from mining areas of Pingdingshan in June 2017. The sampling sites were chosen near three local mines (Hugou-RA, Zaoyuan-RB, Bishan mines-RC). The sample number and GPS coordinates of Pingdingshan area are shown in Table 1. The soil samples were air-dried and then passed through $<2 \mathrm{~mm},<0.25 \mathrm{~mm}$ and $<0.15 \mathrm{~mm}$ sieves. The wheat samples were washed with deionized water, separated into roots and straws, and dried at $75^{\circ} \mathrm{C}$ until constant weight.

Table 1. Sample number and GPS coordinates in Pingdingshan area

\begin{tabular}{c|c|c|c}
\hline Sample name & GPS coordinates & Sample name & GPS coordinates \\
\hline RA-1 & $33.7576929013,113.3456307421$ & RB-7 & $33.7772575173,113.3553975642$ \\
RA-2 & $33.754610741,113.3564701998$ & RB-8 & $33.7720293931,113.3683628691$ \\
RA-3 & $33.7498132802,113.3494517421$ & RB-9 & $33.757254742,113.3572521998$ \\
RA-4 & $33.754610741,113.3564701998$ & RB-10 & $33.7669667372,113.3614036575$ \\
RA-5 & $33.7498132801,113.3494517422$ & RB-11 & $33.755858741,113.3606531998$ \\
RA-6 & $33.7498132802,113.3494517421$ & RB-12 & $33.7672397372,113.3615656575$ \\
RA-7 & $33.7528111219,113.3536091998$ & RB-13 & $33.7772575173,113.3553975642$ \\
RA-8 & $33.7525591219,113.3533481998$ & RB-14 & $33.757254741,113.3572521998$ \\
RA-9 & $43.2086443635,116.6611639959$ & RB-15 & $33.7772575173,113.3553975642$ \\
RA-10 & $33.767433359,113.3566805642$ & RC-01 & $33.7501588052,113.3748027507$ \\
RA-11 & $33.7621259603,113.3745851151$ & RC-02 & $33.7503669635,113.3684036575$ \\
RA-12 & $33.7672397372,113.3615656575$ & RC-03 & $33.7503669635,113.3684036575$ \\
RA-13 & $33.7672397372,113.3615656575$ & RC-04 & $33.7580789603,113.3724291151$ \\
RA-14 & $33.7731903931,113.3681138691$ & RC-05 & $33.7580789603,113.3724291151$ \\
RA-15 & $33.7772575173,113.3553975642$ & RC-06 & $33.7580789603,113.3724291151$ \\
RB-1 & $33.757254741,113.3572521998$ & RC-07 & $33.7503669635,113.3684036575$ \\
RB-2 & $33.7660787372,113.3618146575$ & RC-08 & $33.755858741,113.3606531998$ \\
RB-3 & $33.757254741,113.3572521998$ & RC-09 & $33.7549999603,113.3749691151$ \\
RB-4 & $33.757254741,113.3572521998$ & RC-10 & $33.7550169603,113.3749571151$ \\
RB-5 & $33.766244359,113.3566705642$ & RC-11 & $33.7549549603,113.374636112$ \\
RB-6 & $33.757254741,113.3572521998$ & RC-12 & $33.7551279603,113.3750131151$ \\
\hline
\end{tabular}

\section{Soil physicochemical analyses}

Soil $\mathrm{pH}$ was measured by a $\mathrm{pH}$ detector in a 1:2.5 soil/water suspension (w/v). SOM (soil organic matter) was determined using the potassium dichromate volumetric method. Particle size was analyzed using a Mastersizer 3000 device (Cai et al., 2015). 


\section{Soil available Cd}

Since it is available $\mathrm{Cd}$ rather than total $\mathrm{Cd}$ that matters in $\mathrm{Cd}$ toxicity, here available $\mathrm{Cd}$ was focused. Cd extracted by passive sampling methods such as diethylene triamine penlaacetic acid (DTPA) and DGT can be considered as available $\mathrm{Cd}$ in this work.

\section{DGT deployment}

DGT developed in 1994 by British scientists Davison and Zhang Hao is a contaminant in-situ research technique based on Fick's first law of diffusion. With DGT, the bioavailability of heavy metals can be studied by simulating the heavy metal absorption by plants or other organisms, and the results reflect both static processes (soil particles and soil solutions) and dynamic processes (Luo et al., 2011).

Compared with other traditional morphological analysis techniques, DGT can more efficiently measure the biological effective states of heavy metals in the nature and better reflect the heavy metals absorbed by organisms.

The DGT device consists of an innermost adsorption layer, a diffusion layer covered with specific thickness, and protective filter membranes (Wei et al., 2018).

As the adsorbent in the adsorption film has strong binding capacity with specific phosphorus and metals (metalloid), the target substance (analyte) in the solution can be rapidly and irreversibly fixed on the binding phase and consumed through the diffusion membrane.

Based on Fick's first law (Zhou et al., 2011), the diffusion flux $F$ of the analyte is:

$$
\mathrm{F}=\mathrm{D} \partial \mathrm{C} / \partial \mathrm{x}
$$

where $\mathrm{D}$ is the diffusion coefficient of the tested substance in the diffusion membrane; $\mathrm{C}$ is the concentration of the test substance in the solution.

The time-averaged concentration of the target substance measured by DGT can be calculated as follows:

$$
\mathrm{C}_{\mathrm{DGT}}=\mathrm{M} \Delta \mathrm{g} / \mathrm{DAt}
$$

where $\mathrm{M}$ is the amount of the target substance in the adsorbent, $\Delta \mathrm{g}$ is the thickness of the diffusive layer, $\mathrm{A}$ is the area of the DGT device window, and $\mathrm{t}$ is the adsorption time.

\section{Soil and heavy metal determination}

Air-dried soil samples over a 2-mm nylon sieve were weighed (20 g) and placed into 250-mL plastic containers (Fan et al., 2010).

Then deionized water with the maximum field water holding capacity of $70 \%$ was added under full stirring. The plastic wrap was covered to prevent moisture and evaporation, followed by equilibration at $25^{\circ} \mathrm{C}$ constantly for $48 \mathrm{~h}$.

After that, a small amount of the treated soil (about $3 \mathrm{~g}$ ) was placed with a clean plastic spoon into the round hole of the DGT device and gently shaken parallel on the table surface, making the soil fully contact with the filter surface. Soil was further added until the inner cavity was filled.

The loaded DGT device was transferred to a ziplock bag added with a small amount of deionized water in advance, and the bag mouth was semi-closed (Xu et al., 2004). 
After placement at a constant temperature for $24 \mathrm{~h}$, the soil was removed and the DGT device was rinsed with deionized water. Then the fixed membrane was removed into the ziplock bag, and minor deionized water was dripped to wet it. After sealing, it was stored at $4{ }^{\circ} \mathrm{C}$ for analysis.

\section{Single and comprehensive pollution indices}

The soil pollution degree of each metal was measured using the single pollution index $\left(P_{i}\right)$, which is the ratio of the heavy metal concentration in the contaminated soil to that in the reference soil. $P_{i}$ was calculated as follows (Cai et al., 2015; Yang et al., 2012):

$$
P_{i}=\frac{C_{i}}{C_{o}}
$$

where $C_{i}$ and $C_{o}$ are the heavy metal concentrations in the contaminated soil and the reference soil, respectively. The soil comprehensive pollution status for all the heavy metals was calculated as the Nemero comprehensive pollution index $P_{c}$. The result not only considers the average pollution level of various heavy metals, but also indicates the most serious pollution in the soil contributed by single heavy metals. $P_{c}$ was calculated as follows (Zhou et al., 2011; Chen et al., 2014; Gil-Sotres et al., 2004):

$$
P_{c}=\sqrt{\frac{\left(\overline{P_{i}}\right)^{2}+\max \left(P_{i}\right)^{2}}{2}}
$$

\section{Potential ecological hazard index}

The potential ecological hazard index is based on the characteristics, environmental migration and sedimentation of heavy metals and evaluates heavy metals in soil or sediments from the perspective of sedimentology. This index considers the soil contents of heavy metals and combines ecology, environmental science and biotoxicology (Fan et al., 2003; Li et al., 2014). It comprehensively analyzes the heavy metal migration and transformation in soils and sediments and evaluates the sensitivity of geographical regions to heavy metals and the differences in background values of geographical regions. The degree of potential ecological hazard eliminates the influence of geographical differences (Xiong et al., 2017; Wang et al., 2017), reflects the relative contribution of biological effectiveness and spatial differences, and uncovers the potential impact of heavy metals on the ecoenvironment. It is suitable for largescale comparison of sediments and soils (Xu et al., 2004). Relevant formulas are:

$$
\begin{gathered}
\mathrm{RI}=\sum_{i=1}^{n} E_{r}^{i} \\
E_{r}^{i}=T_{r}^{i} \times C_{f}^{i} \\
C_{f}^{i}=\frac{c_{g}^{i}}{c_{n}^{i}}
\end{gathered}
$$


where $E_{r}^{i}$ is a potential ecological hazard individual coefficient; $T_{r}^{i}$ is the toxicity response coefficient of a certain metal based on Hakanson's standardized heavy metal toxicity coefficient $(\mathrm{Cd}=30, \mathrm{~Pb}=5, \mathrm{Zn}=1) ; C_{r}^{\bar{i}}$ is the single pollution coefficient; $C_{s}^{\bar{i}}$ is the measured heavy metal content in surface soil; $C_{n}^{i}$ is the reference value (from National Secondary Standard for Soil Environmental Quality).

\section{Results and discussion}

\section{Soil properties and contents of metals}

The general characteristics of the soils are shown in Table 2. Soil $\mathrm{pH}$ ranges from 5.2 to 8.3. In RA, the soils are weakly alkaline, with $\mathrm{pH}$ between 7.5 and 8.3. In RB, the majority of the soils are acidic, with $\mathrm{pH}$ between 5.2 and 6.6. As for $\mathrm{RC}$, the $\mathrm{pH}$ is mainly in the neutral range, with the mean of 7.3. The soil organic carbon (OC) in the research areas ranges between $1.9 \%$ and $9.2 \%$, which indicates the difference in soil fertilization degree. The Cd content ranges between 0.13 and $0.4 \mathrm{mg} \cdot \mathrm{kg}^{-1}$, with only one sample from RB exceeding farmland soil pollution risk screening value (GB 156182008). The $\mathrm{Zn}$ content ranges between 50.7 and $125.1 \mathrm{mg} \cdot \mathrm{kg}^{-1}$, while the $\mathrm{Pb}$ content ranges between 15.5 and $38.2 \mathrm{mg} \cdot \mathrm{kg}^{-1}$.

Table 2. General characteristics of soils collected from the study area

\begin{tabular}{|c|c|c|c|c|c|c|c|c|}
\hline \multirow{2}{*}{ Sites } & & \multirow{2}{*}{$\mathbf{p H}$} & \multirow{2}{*}{$\mathrm{OC}(\%)$} & \multicolumn{5}{|c|}{ Total concentration $\left(\mathrm{mg} \cdot \mathrm{kg}^{-1}\right)$} \\
\hline & & & & Cd & \multicolumn{2}{|c|}{$\mathbf{Z n}$} & & $\mathbf{P b}$ \\
\hline \multirow{2}{*}{ RA } & Mean & 7.8 & 5.1 & \multirow{2}{*}{$\begin{array}{c}0.16 \\
0.15-0.19\end{array}$} & \multirow{2}{*}{\multicolumn{2}{|c|}{$\begin{array}{c}69.8 \\
61.9-79.8 \\
\end{array}$}} & \multirow{2}{*}{\multicolumn{2}{|c|}{$\begin{array}{c}34.8 \\
30.8-38.2\end{array}$}} \\
\hline & Range & $7.5-8.3$ & $2.6-9.2$ & & & & & \\
\hline \multirow{2}{*}{$\mathrm{RB}$} & Mean & 5.8 & 4.1 & \multirow{2}{*}{$\begin{array}{c}0.18 \\
0.13-0.4\end{array}$} & \multirow{2}{*}{\multicolumn{2}{|c|}{$\begin{array}{c}67.9 \\
50.7-125.1\end{array}$}} & \multirow{2}{*}{\multicolumn{2}{|c|}{$\begin{array}{c}22.6 \\
15.5-35.5\end{array}$}} \\
\hline & Range & $5.2-6.6$ & $1.9-6.6$ & & & & & \\
\hline \multirow{2}{*}{$\mathrm{RC}$} & Mean & 7.3 & 5.4 & \multirow{2}{*}{$\begin{array}{c}0.15 \\
0.1-0.3\end{array}$} & \multirow{2}{*}{\multicolumn{2}{|c|}{$\begin{array}{c}66.9 \\
57.4-94.9\end{array}$}} & \multirow{2}{*}{\multicolumn{2}{|c|}{$\begin{array}{c}26.6 \\
17.7-35.7\end{array}$}} \\
\hline & Range & $6.7-8.3$ & $2.9-7.3$ & & & & & \\
\hline \multicolumn{4}{|c|}{ Soil background value of Henan Province ${ }^{1}$} & & 0.064 & 62. & & 21.8 \\
\hline \multirow{4}{*}{ Standard limit } & \multirow{4}{*}{\multicolumn{3}{|c|}{ Environmental quality standard for soils ${ }^{2}$}} & & $0.25^{\mathrm{a}}$ & 150 & & $80^{a}$ \\
\hline & & & & & $0.30^{\mathrm{b}}$ & 200 & & $80^{\mathrm{b}}$ \\
\hline & & & & & $0.45^{\mathrm{c}}$ & 250 & & $80^{c}$ \\
\hline & & & & & $0.80^{\mathrm{d}}$ & 300 & & $80^{d}$ \\
\hline
\end{tabular}

${ }^{1}$ The soil background value of Henan province is derived from literature (Shao et al., 1998)

${ }^{2}$ The standard value of soil environmental quality originates from the secondary standard of soil environmental quality standard (GB15618-2008), a is soil $\mathrm{pH}<5.50$, b is pH between 5.50 and 6.50, c is soil $\mathrm{pH}$ between 6.50 and 7.50 , and $\mathrm{d}$ is the corresponding quality standard when soil $\mathrm{pH}>7.50$

Table 3 shows the metal contents measured by DTPA and DGT. The ranges of Cd, $\mathrm{Zn}$ and $\mathrm{Pb}$ are $2.5-11.1,85.3-520.2$ and $0.65-4.88 \mu \mathrm{g} \cdot \mathrm{kg}^{-1}$ respectively (DTPA), and 2.35.5, 57.1-491.3 and 1.1-9.4 $\mu \mathrm{g} \cdot \mathrm{kg}^{-1}$ respectively (DGT). DTPA has higher extraction capacity than DGT, which may be related to the different chemical properties of the extractants. DTPA is an efficient chelating agent with strong extraction ability and can extract water-soluble, exchange, mineral-bound and organic complex heavy metals in soil. 
Table 3. Contents of metals measured using DTPA $\left(C_{D T P A}\right)$ and DGT technique $\left(C_{D G T}\right)$

\begin{tabular}{c|c|c|c|c|c|c|c}
\hline \multirow{2}{*}{ Sites } & & \multicolumn{3}{|c|}{$\mathbf{C D T P A}\left(\boldsymbol{\mu g} \cdot \mathbf{k g}^{-\mathbf{1}}\right)$} & \multicolumn{3}{c}{$\mathbf{C}_{\text {DGT }}\left(\boldsymbol{\mu g} \cdot \mathbf{k g}^{-\mathbf{1}}\right)$} \\
\cline { 3 - 8 } & & $\mathbf{C d}$ & $\mathbf{Z n}$ & $\mathbf{P b}$ & $\mathbf{C d}$ & $\mathbf{Z n}$ & $\mathbf{P b}$ \\
\hline \multirow{2}{*}{$\mathrm{RA}$} & Mean & 4.0 & 190.0 & 3.8 & 3.3 & 176.3 & 4.0 \\
& Range & $3.5-6.1$ & $85.3-300.1$ & $2.7-4.9$ & $2.3-5.5$ & $88.8-491.3$ & $1.9-8.2$ \\
\hline \multirow{2}{*}{$\mathrm{RB}$} & Mean & 5.1 & 171.1 & 3.04 & 2.5 & 76.5 & 2.5 \\
& Range & $3.1-11.1$ & $61.7-412.3$ & $0.7-3.8$ & $3.5-5.5$ & $76.5-242.0$ & $1.9-5.50$ \\
\hline \multirow{2}{*}{$\mathrm{RC}$} & Mean & 5.0 & 337 & 3.4 & 3.0 & 115.7 & 4.5 \\
& Range & $2.5-6.8$ & $41.5-520.2$ & $0.8-4.5$ & $2.4-4.3$ & $57.1-178.3$ & $1.1-9.4$ \\
\hline
\end{tabular}

Tables 4 and 5 show the bioavailable concentrations of $\mathrm{Zn}, \mathrm{Cd}, \mathrm{Pb}$ in the DGT resin eluent and the concentrations of heavy metals measured by DTPA. DTPA extractable heavy metals fraction, as a form of heavy metals with high biological effectiveness, can be used as an effective index of heavy metal pollution in similar soil by its rapid and convenient leaching (Yang et al., 2012; Lu and Zhao, 2017). DTPA can extract watersoluble, exchangeable, adsorptive, organic stationary and partially-oxidized heavy metals from soil, which is considered to be a highly bioactive form related to its total amount. The available heavy metals measured by DGT include the free state of soil solution and the unstable organic and inorganic complex state released from the surface of soil particles (Chen et al., 2012; Bernalte et al., 2013). The average extraction rates (i.e. the percentage of extracted heavy metal content in the total amount of this heavy metal) of $\mathrm{Zn}, \mathrm{Cd}$ and $\mathrm{Pb}$ are $3.18 \%, 30.46 \%$ and $13.03 \%$, respectively in DTPA, and $0.21 \%, 2.01 \%$ and $0.02 \%$, respectively in DGT.

Table 4. $C_{D G T}$ and $C_{D T P A}$ of $\mathrm{Zn}, \mathrm{Cd}$ and $\mathrm{Pb}$

\begin{tabular}{c|c|c|c|c|c|c}
\hline \multirow{2}{*}{ Sites } & \multicolumn{3}{|c|}{$\boldsymbol{C}_{\boldsymbol{D G} \boldsymbol{T}}$} & \multicolumn{3}{c}{$\boldsymbol{C}_{\boldsymbol{D T P A} \boldsymbol{A}}$} \\
\cline { 2 - 6 } & $\mathbf{Z n}$ & $\mathbf{C d}$ & $\mathbf{P b}$ & $\mathbf{Z n}$ & $\mathbf{C d}$ & $\mathbf{P b}$ \\
\hline 1 & 117.25 & 2.27 & 8.25 & 2.39 & 0.04 & 4.00 \\
2 & 126.16 & 3.68 & 3.38 & 2.49 & 0.04 & 4.88 \\
3 & 491.39 & 3.60 & 2.09 & 1.70 & 0.04 & 3.02 \\
4 & 316.63 & 5.52 & 2.89 & 3.01 & 0.04 & 4.65 \\
5 & 153.30 & 2.87 & 4.98 & 2.11 & 0.04 & 4.49 \\
6 & 120.56 & 2.94 & 2.39 & 1.25 & 0.04 & 2.93 \\
7 & 123.72 & 2.82 & 2.68 & 1.63 & 0.04 & 4.09 \\
8 & 163.01 & 3.71 & 5.13 & 2.14 & 0.04 & 4.47 \\
9 & 116.85 & 2.79 & 1.94 & 2.52 & 0.04 & 3.84 \\
10 & 161.59 & 2.50 & 3.97 & 0.97 & 0.05 & 2.99 \\
11 & 136.34 & 2.79 & 4.97 & 0.85 & 0.05 & 2.67 \\
12 & 88.76 & 4.44 & 5.48 & 1.70 & 0.06 & 3.48 \\
13 & 136.10 & 3.22 & 3.85 & 1.39 & 0.05 & 3.19 \\
14 & 97.44 & 2.75 & 4.49 & 0.61 & 0.03 & 0.65 \\
15 & 177.21 & 3.28 & 5.49 & 1.55 & 0.04 & 2.30 \\
16 & 132.24 & 2.48 & 4.95 & 1.29 & 0.05 & 2.85 \\
17 & 184.63 & 12.01 & 5.03 & 1.69 & 0.07 & 3.10 \\
18 & 162.93 & 2.65 & 3.62 & 1.09 & 0.05 & 2.30 \\
19 & 124.35 & 2.82 & 3.59 & 0.89 & 0.05 & 3.18 \\
20 & 101.86 & 2.85 & 3.86 & 0.98 & 0.05 & 3.77 \\
\hline
\end{tabular}


Continue table 4. $C_{D G T}$ and $C_{D T P A}$ of $\mathrm{Zn}, \mathrm{Cd}$ and $\mathrm{Pb}$

\begin{tabular}{l|c|c|c|c|c|c}
\hline 21 & 187.55 & 4.11 & 4.45 & 1.56 & 0.03 & 3.39 \\
22 & 139.18 & 3.15 & 5.24 & 1.41 & 0.05 & 3.58 \\
23 & 130.74 & 2.63 & 5.13 & 1.40 & 0.06 & 3.79 \\
24 & 76.51 & 3.25 & 4.97 & 4.37 & 0.05 & 2.59 \\
25 & 128.21 & 2.72 & 2.49 & 1.48 & 0.06 & 3.10 \\
26 & 153.62 & 3.17 & 5.54 & 1.82 & 0.05 & 3.37 \\
27 & 98.63 & 3.02 & 2.55 & 4.72 & 0.11 & 3.54 \\
28 & 159.61 & 5.57 & 3.53 & 1.23 & 0.05 & 3.52 \\
29 & 76.29 & 3.54 & 2.54 & 2.40 & 0.05 & 3.53 \\
30 & 116.06 & 2.44 & 9.41 & 3.67 & 0.05 & 3.51 \\
31 & 57.08 & 2.52 & 1.15 & 5.20 & 0.06 & 3.66 \\
32 & 116.30 & 2.80 & 5.36 & 2.37 & 0.05 & 3.43 \\
33 & 140.60 & 2.56 & 3.97 & 2.15 & 0.05 & 3.34 \\
34 & 150.31 & 2.45 & 7.24 & 1.71 & 0.04 & 2.63 \\
35 & 143.91 & 2.74 & 5.81 & 2.79 & 0.05 & 3.09 \\
36 & 166.08 & 3.75 & 4.42 & 0.41 & 0.02 & 0.83 \\
37 & 108.88 & 4.34 & 3.52 & 4.74 & 0.06 & 3.67 \\
38 & 70.18 & 3.31 & 2.26 & 3.84 & 0.06 & 3.99 \\
39 & 96.73 & 2.77 & 4.12 & 4.84 & 0.07 & 3.93 \\
40 & 178.31 & 2.73 & 6.15 & 4.69 & 0.05 & 4.50 \\
\hline
\end{tabular}

Table 5. Statistical parameter of $C_{D G T}$ and $C_{D T P A}$ of $\mathrm{Zn}, \mathrm{Cd}$ and $\mathrm{Pb}$

\begin{tabular}{c|c|c|c|c|c|c}
\hline \multirow{2}{*}{ Statistic } & \multicolumn{3}{|c|}{$\boldsymbol{C}_{\boldsymbol{D G T}}$} & \multicolumn{3}{c}{$\boldsymbol{C D T P A}$} \\
\cline { 2 - 7 } & $\mathbf{Z n}$ & $\mathbf{C d}$ & $\mathbf{P b}$ & $\mathbf{Z n}$ & $\mathbf{C d}$ & $\mathbf{P b}$ \\
\hline Maximum & 491.39 & 12.01 & 9.41 & 5.20 & 0.11 & 4.88 \\
Minimum & 57.08 & 2.27 & 1.15 & 0.41 & 0.02 & 0.65 \\
Average & 143.18 & 3.39 & 4.32 & 2.23 & 0.05 & 3.35 \\
Standard deviation & 70.41 & 1.57 & 1.67 & 1.29 & 0.01 & 0.85 \\
Coefficient of variation & 0.49 & 0.46 & 0.39 & 0.58 & 0.29 & 0.25 \\
\hline
\end{tabular}

Table 6 presents the soil particle concentration $\left(P_{c}\right)$ in each sampling point, the Rdiff calculated using the 2D DIFS model, and the effective concentration (CE) calculated as the ratio between $C_{D G T}$ and Rdiff. In general, soil $P_{c}$ in the same area is approximately the same, with the lowest $\mathrm{SA}$. The $\mathrm{CE}$ ranks as $\mathrm{Zn}>\mathrm{Pb}>\mathrm{Cd}$, while the heavy metal content extracted by DTPA ranks as $\mathrm{Pb}>\mathrm{Zn}>\mathrm{Cd}$.

The relationships between $\mathrm{Cd}, \mathrm{Zn}, \mathrm{Pb}$ in the roots, straws and that extracted by DGT and DTPA are shown in Figure 1 and Table 7. Although the $C_{D G T}$ of $\mathrm{Cd}, \mathrm{Zn}$ and $\mathrm{Pb}$ in the soil is one to two orders-of-magnitude lower than those extracted by DTPA, $C_{D G T}$ extraction is closer to wheat availability than DTPA extraction, and DTPA extraction may overestimate the concentration of available states, and some of the extracted metals may not be absorbed by wheat. More studies also show DGT better reflects plant uptake than chemical extraction. For example, PUEYO M used DGT to assess the influence factors on cadmium accumulation in rice grains from paddy soils of three parent materials and found that cadmium bioavailability could well be assessed by DGT (Pueyo et al., 2008). Bernd Nowack et al. used DGT to test undisturbed field soils and suggested that DGT can be successfully used under undisturbed field conditions to study the kinetics of metal resupply. 
Table 6. $R_{\text {diff }}$ and $C_{E}$ of metals

\begin{tabular}{|c|c|c|c|c|c|c|c|}
\hline \multirow{2}{*}{ Sample sites } & \multirow{2}{*}{$P_{c} \mathrm{~g} \cdot \mathrm{cm}^{-3}$} & \multicolumn{3}{|c|}{$\boldsymbol{R}_{\text {diff }}$} & \multicolumn{3}{|c|}{$C_{E}\left(\mu \mathrm{g} \cdot \mathrm{L}^{-1}\right)$} \\
\hline & & Cd & $\mathbf{Z n}$ & $\mathbf{P b}$ & Cd & $\mathrm{Zn}$ & $\mathbf{P b}$ \\
\hline 1 & 20.9 & 0.28 & 14.86 & 1.37 & 2.2652 & 117.2454 & 8.2474 \\
\hline 2 & 17.4 & 0.455 & 15.99 & 0.562 & 3.68095 & 126.1611 & 3.38324 \\
\hline 3 & 12.9 & 0.445 & 62.28 & 0.348 & 3.60005 & 491.3892 & 2.09496 \\
\hline 4 & 23.4 & 0.682 & 40.13 & 0.48 & 5.51738 & 316.6257 & 2.8896 \\
\hline 5 & 18.2 & 0.355 & 19.43 & 0.828 & 2.87195 & 153.3027 & 4.98456 \\
\hline 6 & 24.9 & 0.363 & 15.28 & 0.397 & 2.93667 & 120.5592 & 2.38994 \\
\hline 7 & 13.3 & 0.349 & 15.68 & 0.445 & 2.82341 & 123.7152 & 2.6789 \\
\hline 8 & 26.1 & 0.459 & 20.66 & 0.852 & 3.71331 & 163.0074 & 5.12904 \\
\hline 9 & 19.4 & 0.345 & 14.81 & 0.322 & 2.79105 & 116.8509 & 1.93844 \\
\hline 10 & 16 & 0.309 & 20.48 & 0.659 & 2.49981 & 161.5872 & 3.96718 \\
\hline 11 & 20.4 & 0.345 & 17.28 & 0.826 & 2.79105 & 136.3392 & 4.97252 \\
\hline 12 & 15.63 & 0.549 & 11.25 & 0.91 & 4.44141 & 88.7625 & 5.4782 \\
\hline 13 & 22.9 & 0.398 & 17.25 & 0.639 & 3.21982 & 136.1025 & 3.84678 \\
\hline 14 & 28.3 & 0.34 & 12.35 & 0.746 & 2.7506 & 97.4415 & 4.49092 \\
\hline 15 & 29.2 & 0.406 & 22.46 & 0.912 & 3.28454 & 177.2094 & 5.49024 \\
\hline 16 & 32.1 & 0.306 & 16.76 & 0.822 & 2.47554 & 132.2364 & 4.94844 \\
\hline 17 & 20.1 & 1.484 & 23.4 & 0.836 & 12.00556 & 184.626 & 5.03272 \\
\hline 18 & 20.4 & 0.328 & 20.65 & 0.602 & 2.65352 & 162.9285 & 3.62404 \\
\hline 19 & 35.7 & 0.348 & 15.76 & 0.596 & 2.81532 & 124.3464 & 3.58792 \\
\hline 20 & 31.8 & 0.352 & 12.91 & 0.641 & 2.84768 & 101.8599 & 3.85882 \\
\hline 21 & 28.2 & 0.508 & 23.77 & 0.739 & 4.10972 & 187.5453 & 4.44878 \\
\hline 22 & 21.4 & 0.389 & 17.64 & 0.87 & 3.14701 & 139.1796 & 5.2374 \\
\hline 23 & 22.2 & 0.325 & 16.57 & 0.852 & 2.62925 & 130.7373 & 5.12904 \\
\hline 24 & 22.65 & 0.402 & 9.697 & 0.826 & 3.25218 & 76.50933 & 4.97252 \\
\hline 25 & 22 & 0.336 & 16.25 & 0.414 & 2.71824 & 128.2125 & 2.49228 \\
\hline 26 & 27.7 & 0.409 & 30.71 & 0.878 & 3.30881 & 242.3019 & 5.28556 \\
\hline 27 & 13.2 & 0.373 & 12.5 & 0.423 & 3.01757 & 98.625 & 2.54646 \\
\hline 28 & 24.2 & 0.688 & 20.23 & 0.587 & 5.56592 & 159.6147 & 3.53374 \\
\hline 29 & 25.8 & 0.437 & 9.669 & 0.422 & 3.53533 & 76.28841 & 2.54044 \\
\hline 30 & 24.6 & 0.301 & 14.71 & 1.563 & 2.43509 & 116.0619 & 9.40926 \\
\hline 31 & 23.3 & 0.311 & 7.234 & 0.191 & 2.51599 & 57.07626 & 1.14982 \\
\hline 32 & 21.6 & 0.346 & 14.74 & 0.89 & 2.79914 & 116.2986 & 5.3578 \\
\hline 33 & 24 & 0.316 & 17.82 & 0.66 & 2.55644 & 140.5998 & 3.9732 \\
\hline 34 & 25.7 & 78.033 & 872 & 1.202 & 631.287 & 6880.08 & 7.23604 \\
\hline 35 & 26.4 & 0.339 & 18.24 & 0.965 & 2.74251 & 143.9136 & 5.8093 \\
\hline 36 & 24.5 & 0.464 & 21.05 & 0.735 & 3.75376 & 166.0845 & 4.4247 \\
\hline 37 & 18.7 & 0.536 & 13.8 & 0.584 & 4.33624 & 108.882 & 3.51568 \\
\hline 38 & 27 & 0.409 & 8.895 & 0.376 & 3.30881 & 70.18155 & 2.26352 \\
\hline 39 & 33.8 & 0.342 & 12.26 & 0.685 & 2.76678 & 96.7314 & 4.1237 \\
\hline 40 & 21.7 & 0.337 & 22.6 & 1.022 & 2.72633 & 178.314 & 6.15244 \\
\hline
\end{tabular}



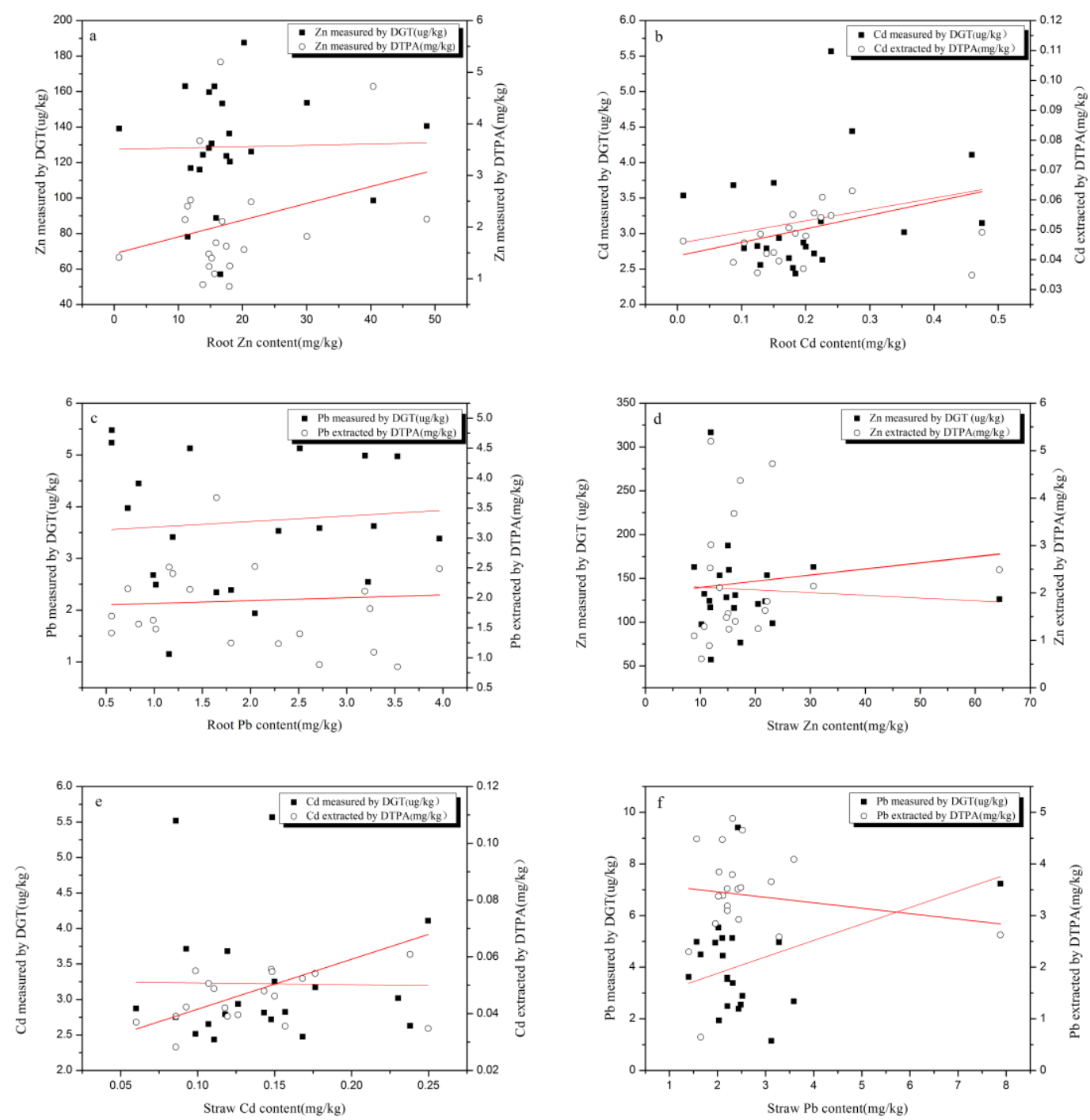

Figure 1. Relationship between heavy metals extracted by DGT and DTPA: relationship between the contents of (a) $\mathrm{Zn}$, (b) $\mathrm{Cd}$, (c) Pb in roots and from DGT and DTPA; relationship between the contents of $(d) \mathrm{Zn},(e) C d$ and (f) Pb in straw and from DGT and DTPA

\section{Environment evaluation}

\section{Single and comprehensive pollution indices}

The results of heavy metal pollution index are shown in Table 8. In terms of $\mathrm{Zn}$, more than half of the samples are at light pollution, while others are still at clean level. In terms of $\mathrm{Cd}$, most of the samples are in mild pollution (Liu et al., 2017; Shi et al., 2013), and only $9.76 \%$ of them are in moderate pollution. Noticeably, 3 samples are in severe pollution, which indicates high risks. As for $\mathrm{Pb}, 53.69$ of the samples are in moderate pollution and others are in mild pollution. The Nemero comprehensive pollution index of 43 samples ranges from 1.22 to 3.36 with a mean of $1.7<2$, indicating the soil is at slight pollution, and $\mathrm{Cd}$ is under the severest pollution.

The $\mathrm{E}_{\mathrm{r}}^{\mathrm{i}}$ and RI were calculated by Equations 3, 4 and 5 (Table 9). The single coefficient of potential ecological hazard and other elements belong to minor ecological hazards. Chu Chunjie et al. pointed out that $\mathrm{Cu}, \mathrm{Zn}, \mathrm{Ni}$ and $\mathrm{Pb}$ induced chronic non- 
carcinogenic health risks (Chen et al., 2017; Bhuiyan et al., 2010), while $\mathrm{Cr}$ had a clear risk of cancer in the soil of hilly slopes around mining areas in Pingdingshan. The results indicate $\mathrm{Zn}$ and $\mathrm{Pb}$ in the soil around the mining areas of Pingdingshan exceed the standard, which is a non-carcinogenic health risk (Yenilmez et al., 2011).

Table 7. Relationship between heavy metals extracted by different extractants and that in wheat

\begin{tabular}{|c|c|c|c|c|}
\hline & & Linear equation & $\mathbf{r}$ & $\mathbf{p}$ \\
\hline \multirow{6}{*}{ Root } & $\mathrm{Zn}_{\text {DGT }}$ & $y=0.6694 x+114.59$ & 0.19 & $<0.01$ \\
\hline & $\mathrm{Zn}_{\text {DTPA }}$ & $y=0.0013 x+1.9466$ & 0.01 & $<0.01$ \\
\hline & $\mathrm{Cd}_{\mathrm{DGT}}$ & $y=2.9972 x+2.6501$ & 0.34 & $<0.01$ \\
\hline & $\mathrm{Cd}_{\mathrm{DTPA}}$ & $y=0.0109 x+0.0455$ & 0.12 & $<0.01$ \\
\hline & $\mathrm{Pb}_{\mathrm{DGT}}$ & $\mathrm{y}=0.371 \mathrm{x}+2.801$ & 0.32 & $<0.01$ \\
\hline & $\mathrm{Pb}_{\mathrm{DTPA}}$ & $y=0.0231 x+1.9169$ & 0.03 & $<0.01$ \\
\hline \multirow{6}{*}{ Straw } & $\mathrm{Zn}_{\text {DGT }}$ & $y=0.1744 x+92.806$ & 0.33 & $<0.01$ \\
\hline & $\mathrm{Zn}_{\text {DTPA }}$ & $y=0.0585 x+1.1555$ & 0.27 & $<0.01$ \\
\hline & $\mathrm{Cd}_{\mathrm{DGT}}$ & $y=3.7437 x+2.3191$ & 0.51 & $<0.01$ \\
\hline & $\mathrm{Cd}_{\mathrm{DTPA}}$ & $y=0.1624 x+0.0259$ & 0.49 & $<0.01$ \\
\hline & $\mathrm{Pb}_{\mathrm{DGT}}$ & $y=0.3985 x+2.8309$ & 0.61 & $<0.01$ \\
\hline & $\mathrm{Pb}_{\mathrm{DTPA}}$ & $y=0.0187 x+3.0632$ & 0.19 & $<0.01$ \\
\hline
\end{tabular}

Table 8. Heavy metal pollution index evaluation results

\begin{tabular}{c|c|c|c}
\hline Heavy metal element & $\mathbf{Z n}$ & $\mathbf{C d}$ & $\mathbf{P b}$ \\
\hline Clean (a) & 0 & 0 & 0 \\
Clean (\%) & 0 & 0 & 0 \\
Still clean (a) & 15 & 0 & 0 \\
Still clean (\%) & 36.59 & 0 & 0 \\
Mild pollution (a) & 26 & 34 & 19 \\
Mild pollution (\%) & 63.41 & 82.93 & 46.34 \\
Moderate pollution (a) & 0 & 4 & 22 \\
Moderate pollution (\%) & 0 & 9.76 & 53.69 \\
Severe pollution (a) & 0 & 3 & 0 \\
Severe pollution (\%) & 0 & 7.32 & 0 \\
\hline
\end{tabular}

Table 9. Farmland soil $E_{r}^{i}$, RI in Pingdingshan mining area

\begin{tabular}{c|c|c|c|c|c|c}
\hline $\mathbf{E}^{\mathbf{C d}_{\mathbf{r}}}$ & $\boldsymbol{E}^{\mathbf{C r}_{\mathbf{r}}}$ & $\boldsymbol{E}^{\mathbf{N i}_{\mathbf{r}}}$ & $\boldsymbol{E}^{\mathbf{C u}_{\mathbf{r}}}$ & $\boldsymbol{E}^{\mathbf{Z n}_{\mathbf{r}}}$ & $\boldsymbol{E}^{\mathbf{P b}_{\mathbf{r}}}$ & $\boldsymbol{R I}$ \\
\hline 37.8 & 0.5 & 0.5 & 1.6 & 0.3 & 4.5 & 45.2 \\
\hline
\end{tabular}

\section{General situation of heavy metal pollution in soil}

The results showed that the average $\mathrm{pH}$ values of wheat fields in the study area were 7.8, 5.8 and 7.3, respectively, in which RA and $\mathrm{RC}$ were at the alkaline level and RB was at the acidic level. According to the statistical results in Table 2, the average content of heavy metal elements in the wheat fields in the three mining areas all 
exceeded the background value of soil elements in Henan province. The average values of $\mathrm{Cd}, \mathrm{Zn}$ and $\mathrm{Pb}$ in the wheat fields in RA mining area were 2.50, 2.81 and 2.34 times of the background value, respectively. The average values of $\mathrm{Cd}, \mathrm{Zn}$ and $\mathrm{Pb}$ in the wheat field in the RB mining area were 1.12, 1.09 and 1.07 times of the background values, respectively. The average values of $\mathrm{Cd}, \mathrm{Zn}$ and $\mathrm{Pb}$ in wheat field in $\mathrm{RC}$ mining area were 1.60, 1.04 and 1.22 times of the background values, respectively. According to the grade ii standard of soil environmental quality standard (GB15618-2008), the average values of $\mathrm{Cd}, \mathrm{Zn}$ and $\mathrm{Pb}$ in wheat fields in $\mathrm{RA}$ mining area were $0.20,0.23$ and 0.44 times of the standard values, respectively. The average values of $\mathrm{Cd}, \mathrm{Zn}$ and $\mathrm{Pb}$ in the wheat field in the RB mining area were 0.60, 0.34 and 0.28 times of the standard values, respectively. $\mathrm{RC}$ mining area of wheat to $\mathrm{Cd}, \mathrm{Zn}$ and $\mathrm{Pb}$ respectively, the average standard value of $0.33,0.27$, and 0.33 times. The soil heavy metal pollution degree of $\mathrm{RB}>\mathrm{RC}>\mathrm{RA}$, and by a single heavy metal pollution degree, $\mathrm{Cd}>\mathrm{Pb}>\mathrm{Zn}$, along with the exploitation of coal mine, the content of soil heavy metal levels in gradually rise, which is consistent with the research results of Chen et al. (2017).

\section{Conclusions}

In this paper, three typical coal mines in Pingdingshan were investigated to study the heavy metal pollution in the surrounding soil and wheat using the diffusive gradients in thin films (DGT) and pentetic acid or diethylene triamine penlaacetic acid (DTPA), and to explore its potential ecological risks. The results show that the soil heavy metal pollution around the main mining areas of Pingdingshan is under different levels. The average soil contents of $\mathrm{Zn}, \mathrm{Cd}$ and $\mathrm{Pb}$ are $68.64,0.68$ and $26.96 \mathrm{mg} \cdot \mathrm{L}^{-1}$, respectively. According to the extraction effect of different extractants. DTPA has higher extraction capacity than DGT, which may be related to the different chemical properties of the extractants. From the average extraction efficiency of different extraction methods for the same heavy metal. The average extraction rates (i.e. the percentage of extracted heavy metal content in the total amount of this heavy metal) of $\mathrm{Zn}, \mathrm{Cd}$ and $\mathrm{Pb}$ are $3.18 \%, 30.46 \%$ and $13.03 \%$, respectively in DTPA, and $0.21 \%, 2.01 \%$ and $0.02 \%$, respectively in DGT. The Nemero comprehensive pollution index shows the soil pollution of heavy metals is slight. The single ecological coefficient of potential ecological hazard indicates the soil pollution degrees of various heavy metals rank as $\mathrm{Cd}>\mathrm{Pb}>\mathrm{Zn}$, and the most serious pollution is $\mathrm{Cd}$, which is close to medium ecohazards, while other heavy metals are under minor ecological hazards.

Acknowledgements. We sincerely appreciate the laboratory and diving assistance by the Science \& Technology Innovation Team in Universities of Henan Province (19IRTSTHN029). This work was supported by the National Science Foundation for Young Scholars of China under Grant [41601522], China Postdoctoral Science Foundation under Grant [2017M612387], and Henan Postdoctoral Science Foundation under Grant [001701033].

\section{REFERENCES}

[1] Behaddya, M. L., Hadjel, M. (2014): Spatial distribution and contamination assessment of heavy metals in surface soils of Hassi Messaoud, Algeria. - Environmental Earth Sciences 71(3): 1473-1486. 
[2] Bernalte, E., Marn, S. C., Pinilla, G. E. (2013): High-Throughput mercury monitoring in indoor dust microsamples by bath ultrasonic extraction and anodic stripping voltammetry on gold nanoparticles-modified screen-printed electrodes. - Electroanalysis 25(1): 289294.

[3] Bhuiyan, M. A., Parvez, L., Isiam, M. A. et al. (2010): Heavy metal pollution of coal mine-affected agricultural soils in the northern part of Bangladesh. - Journal of Hazardous Materials 173(1-3): 384-392.

[4] Cai, L. M., Xu, Z. C., Qi, J. Y., Feng, Z. Z., Xiang, T. S. (2015): Assessment of exposure to heavy metals and health risks among residents near Tonglushan mine in Hubei, China. - Chemosphere 127: 127-135.

[5] Chen, F., Dong, Z. Q., Wang, C. C. et al. (2017): Heavy metal contamination of soils and crons near a zinc smelter. - Environmental Science 38(10): 4360-4369.

[6] Chen, J., Sun, Q., Yao, Y. et al. (2014): Comparison of DGT technique with traditional methods for evaluating cadmium bioavailability in soils with combined pollution. Research of Environmental Sciences 27(10): 1172-1179.

[7] Fan, S. X., Gan, Z. T., Li, M. J. (2010): Progress in evaluation methods of heavy metal pollution in soil. - China's Agronomy Bulletin 26(17): 310-315.

[8] Fan, Y. H., Lu, Z. H., Cheng, J. L. et al. (2003): Major ecological and environmental problems and the ecological reconstruction technologies of the coal mining areas in China. - Acta Ecologica Sinica 23(10): 2144-2152.

[9] Gil-Sotres, F., Trasar-Cepeda, C., Leirós, M. C., Seoane, S. (2004): Different approaches to evaluating soil quality using biochemical properties. - Soil Biology and Biochemistry 37(5): 877-887.

[10] Li, B. J., Wang, L. C., Long, M. Z. et al. (2014): Evaluation of coal mining wasteland polluted by heavy metal of Huaxi District in Guiyang City. - Guizhou Agricltural Sciences 42(4): 130-135.

[11] Liu, D., Zhao, Y. H., Zhou, D. et al. (2017): Ecological risk assessment of heavy metals pollution in a tungsten mine soil in south of Jiangxi Province. - Environmental Chemistry 36(7): 1556-156.

[12] Lu, J., Zhao, X. Q. (2017): Characteristics and ecological risk assessment of polluted soil by heavy metals in Shizishan, Tongling. - Environmental Chemistry 36(9): 1958-1967.

[13] Luo, J., Wang, X. et al. (2011): Theory and application of diffusive gradients in thin films in soils. - Journal of Agro-Environment Science 30(2): 205-213.

[14] Pueyo, M., Mateu, J., Rigol, A. et al. (2008): Use of the modified BCR three-step sequential extraction procedure for the study of trace element dynamics in contaminated soils. - Environmental Pollution 152(2): 330-341.

[15] Shao, F., Zhou, H. (1998): Soil environmental background value of main elements in Henan province. - Henan agriculture (10): 29.

[16] Shi, Z. F., Wang, L. (2013): Contents of soil heavy metals and evaluation on the potential pollution risk in Shenmu mining area. - Journal of Agro-Environment Science 32(6): $1150-1158$.

[17] Wang, Y. Q., Bai, Y. R., Wang, J. Y. (2016): Distribution of urban soil heavy metal and pollution evaluation in different functional zones of Yinchuan City. - Environmental Sciene 37(2): 710-716.

[18] Wei, T., Guan, D., Fang, W. et al. (2018): Theory and application of diffusive gradients in thin-films (DGT) in the environment III: theoretical basis and application potential in phytoavailability assessment. - Journal of Agro-Environment Science 7(5): 841-849.

[19] Xiong, S., Gui, H. R., Peng, W. H. (2017): Accumulation and health risk assessment of heavy metals in soil-maize system from coal mining area. - Science Technology and Engineering 17(8): 80-86.

[20] Xu, Z. Q., Ni, J. S., Zhang, C. J. (2004): Assessment of heavy metals in sediments of Jinshajiang River in Panzhihua area by pollution load index method. - Sichuan Environment 23(3): 64-67. 
[21] Yang, S., Yuan, Z. et al. (2012): Heavy Metal contamination and bioavailability in Huayuan manganese and lead/zinc mineland, Xiangxi. - Environmental Sciences 33(5): 1718-1724.

[22] Yenilmez, F., Kuter, N., Emil, M. K. et al. (2011): Evaluation of pollution levels at an abandoned coal mine site in Turkey with the aid of GIS. - International Journal of Coal Geology 86(1): 12-19.

[23] Zhou, S. L., Li, R. H., Wu, S. H. (2011): Study on Relations Between the Economic Development and the Spatial and Temporal Variation of Heavy Metals in Agricultural Land. - China Land Press, Beijing. 